\title{
ARTIGOS
}

CIDADE, HISTÓRIA E CULTURA

\section{AS ESTRATÉGIAS DE MARKETING URBANO DO PORTO DIGITAL}

\author{
Tarciso Binoti Simas* \\ Sônia Azevedo Le Cocq d'Oliveira \\ Carlos Maviael de Carvalho* \\ *Universidade Federal do Sul e Sudeste do Pará, Instituto de Engenharia do Araguaia, Santana do \\ Araguaia, PA, Brasil \\ **Universidade Federal do Rio de Janeiro, Faculdade de Arquitetura e Urbanismo, Programa de \\ Pós-graduação em Urbanismo, Rio de Janeiro, RJ, Brasil
}

\section{Resumo}

Porto Digital é uma política implantada no ano de 2000 e gerida por uma Organização Social (OS) que tinha como objetivos iniciais inserir Pernambuco no cenário tecnológico e contribuir com a revitalização do Bairro do Recife. Ao longo dessas duas décadas, essa OS se consolidou como um importante ator no planejamento urbano, ao associar conceitos em moda no debate sobre inovação. O objetivo deste trabalho é demonstrar como essas narrativas são instrumentalizadas como marketing urbano. Trata-se de uma pesquisa explicativa sobre a construção, a evolução e os principais impactos do Porto Digital, graças à coleta de dados bibliográficos, documentais, entrevistas e observação. Percebe-se, assim, um processo de gentrificação com manipulação da identidade, êxodo de parte da população e valorização de imóveis a serem consumidos sobretudo por empresas. Entende-se que a instrumentalização desse debate inovativo como marketing urbano permite tanto impulsionar negócios quanto servir como cortina de fumaça para os problemas sociais.

Palavras-chave

Marketing Urbano; Gentrificação; Economia de Aglomeração; Economia Criativa; Produção Maker; Bairro do Recife. 


\title{
ARTICLES
}

\section{CITY, HISTORY AND CULTURE}

\section{CITY MARKETING STRATEGIES OF PORTO DIGITAL}

\author{
Tarciso Binoti Simas*
}

Sônia Azevedo Le Cocq d'Oliveira

Carlos Maviael de Carvalho*

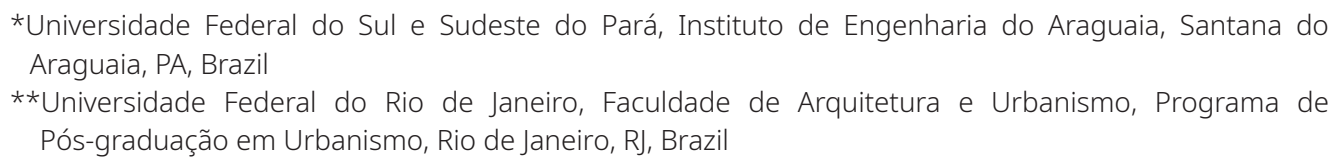

\begin{abstract}
Porto Digital was a policy implemented in 2000, and managed by a social organization (SO) with the initial objectives of inserting Pernambuco into the technology scenario and contributing to the revitalization of the district in the city of Recife known as Bairro do Recife. Over the past two decades, this SO has established itself as a central actor in urban planning, by associating stateof-the-art concepts into the debate on innovation. The aim of this paper is to demonstrate how these narratives have been used as city marketing. This was an explanatory research on the construction, evolution and main impacts of Porto Digital, enabled through the collection of bibliographic, documentary, interview and observational data. It may be perceived that a gentrification process has taken place with identity manipulation, an exodus of part of the population and the valorization of real estate chiefly for the consumption of companies. It may be understood that the instrumentalization of this innovation debate as city marketing has both boosted businesses and served as a smokescreen for social problems.

Keywords

City Marketing; Gentrification; Agglomeration Economy; Creative Economy; Maker Production; Bairro do Recife.
\end{abstract}




\section{AS ESTRATÉGIAS DE MARKETING URBANO DO PORTO DIGITAL}

Tarciso Binoti Simas

Sônia Azevedo Le Coca d'Oliveira

Carlos Maviael de Carvalho

Introdução

Porto Digital é uma política pública criada pelo governo de Pernambuco no ano de 2000 com os objetivos iniciais de inserir o estado no "cenário tecnológico e inovador" e de contribuir com a revitalização econômica e urbana do Bairro do Recife especificamente. Naquele momento, desenrolava-se ali um processo de gentrificação voltado ao entretenimento e ao turismo, com êxodo de parte de sua população (LEITE, 2006; MORIM DE MELO, 2003). No entanto, havia certa dificuldade de entrada de nova população que consumisse e reformasse os imóveis históricos. A ideia de um parque tecnológico uniu-se ao processo de revitalização desse sítio histórico, com maior aceitação da entrada de empresas do que de população residente para custear a recuperação de imóveis, considerando que geralmente o metro quadrado de escritórios é mais caro do que o residencial. Em 2001, a Associação Núcleo de Gestão do Porto Digital foi qualificada como Organização Social (OS) responsável por implantar o modelo de governança, promover a infraestrutura e instalar incubadoras no Bairro do Recife. Desde então, essa governança tem demonstrado ser muito dinâmica em razão de alguns fatores: i) sobrevivência a diferentes gestões políticas e momentos econômicos; ii) novas responsabilidades no ramo imobiliário e no planejamento urbano; e iii) pela renovação constante de suas estratégias com base em conceitos em voga relativos ao debate sobre inovação ao longo das duas décadas decorridas. Entretanto, esse contexto tem contribuído para o processo de gentrificação do Bairro do Recife resultante da manipulação de sua identidade, da valorização imobiliária, de êxodo de parte da população de baixa renda e da entrada de nova população, sobretudo nas empresas privadas que vêm se implantando ali. 
Assim, o objetivo deste artigo é demonstrar como essas narrativas são instrumentalizadas como marketing urbano. Para realizar este estudo de caso sobre o Porto Digital, apresenta-se a seguir o referencial teórico que cruza as questões de marketing urbano e gentrificação e os conceitos em voga no debate inovativo desde o final do século XX.

\section{A inovação como marketing urbano}

Com a escassez na geração de renda e de empregos após a crise dos anos 1970 e em recursos federais na gestão liberal do presidente Ronald Reagan (1981-89), algumas cidades estadunidenses adotaram incentivos fiscais e urbanísticos e de marketing com o propósito de aumentar a competitividade na atração de investidores para a realização de Parceria Público-Privada (PPP) em projetos de revitalização urbana e econômica de bairros deprimidos de investimento. Esse "modelo" fragmentado de política urbana foi “exportado” para a Grã-Bretanha, depois para o restante da Europa e outras partes do mundo, incentivando o marketing urbano, ou city marketing, como uma nova agenda econômica local voltada à construção de uma "imagem de marca" para atração de investidores, turistas e consumidores (COMPANS, 2005). Para Delgado (2010, p. 40; tradução dos autores), o objetivo do marketing urbano "não é outro que (a venda) da própria cidade, mercadoria que requer uma adequada combinação de teorização das aparências e um vocabulário devidamente trufado de invocações aos valores abstratos do pensamento politicamente correto".

De acordo com Vainer (2013), esse modelo de planejamento estratégico foi inspirado em conceitos e técnicas do planejamento empresarial da Harvard Business School, e, segundo seus idealizadores ou seguidores, as cidades estariam então submetidas às mesmas condições e desafios das empresas privadas. Lima Junior (2010) aponta que a administração pública, antes vista como burocrática, assume uma postura de gestão, estratégia, estrutura e promoção semelhante à da administração de empresas (principalmente as globais) e passa a oferecer externalidades e maior publicidade para atrair a preferência de capitais em fluxo. Nesse meio técnico-científico-informacional, Santos (2006, p. 160) afirma que "os espaços assim requalificados atendem sobretudo aos interesses dos atores hegemônicos da economia, da cultura e da política e são incorporados plenamente às novas correntes mundiais”. Arantes (2013, p. 16) destaca a instrumentalização de construções públicas monumentais ou megaempreendimentos-âncora culturais que se tornaram instrumentos de poder no mundo dos negócios e das cidades globais, desbravando "uma nova fronteira de acumulação de poder e dinheiro - o negócio das imagens". 
Com isso, em operações urbanas de bairros deprimidos de investimentos, novas infraestruturas, eventos, equipamentos coletivos e qualidade em espaço público são implantados e apresentados como fatores de "sucesso" no que se refere à melhoria da qualidade de vida. Entretanto, parte dessas melhorias se restringe aos cidadãos com poder de compra. Por outro lado, a população de baixa renda começa a vivenciar processos de gentrificação, um termo aportuguesado da palavra inglesa gentrification, derivação de gentry, que pode ser traduzida como "alta burguesia” ou "pequena nobreza”. Esse conceito foi construído pela socióloga Ruth Glass, ao descrever, no livro London: aspects of change, de 1964, um fenômeno de renovação de moradias no bairro londrino de Islington, com o êxodo dos habitantes da classe trabalhadora (OMM, 2015).

Para Smith (2015), desde as décadas de 1950-60, a gentrificação deixou de ser um fenômeno local do mercado de moradia e se generalizou, nos anos 1990, como uma estratégia urbana neoliberal pelos circuitos globais de capital e circulação cultural. Smith estabelece uma importante analogia entre processos de gentrificação e o avanço na fronteira de colonização no oeste estadunidense nos séculos XVIII e XIX. Para ele, embora não seja um avanço geográfico absoluto, o "avanço na fronteira da gentrificação” constituiria uma reconquista de territórios deprimidos de investimentos por bancos, promotores imobiliários, cadeias de distribuição, Estado etc. E essa "recolonização" é feita, geralmente, pela classe média de cor branca sobre a população de baixa renda de cor não branca (SMITH, 2012).

De modo mais abrangente, entende-se gentrificação como um processo que converte um bairro desvalorizado - opção de moradia e de trabalho da população de baixa renda - em uma mercadoria valorizada a ser consumida pela classe média, por empresas e turistas, ampliando, assim, a reprodução do capital na cidade em negócios turísticos, de entretenimento e/ou imobiliário. Em geral, esse fenômeno é estimulado por iniciativas pública e/ou privada e está associado ao êxodo de grande parte da população de baixa renda, seja de forma "silenciosa", em decorrência do aumento do custo de vida, sobretudo de aluguel, seja de forma mais incisiva, por meio da remoção e da demolição de antigos cortiços, ocupações, vilas e prédios inteiros pelo poder público e/ou pelo mercado imobiliário para a construção de novos empreendimentos (SIMAS, 2018).

Para se diversificarem nesse tratamento da cidade como um negócio, as estratégias de marketing urbano incorporam discursos cada vez mais sofisticados para a "disputa" por certa originalidade e pela criação de uma "marca”. Esse marketing aumenta o quociente de capital simbólico e de traços distintivos que, segundo Harvey (2014), fundamentam melhor as reivindicações de singularidade, autenticidade, particularidade e especificidade e se traduzem em rendas de monopólio. 
Vale ressaltar também a expansão do lucrativo mercado de consultoria internacional que alimenta o "otimismo" no planejamento que, por sua vez, significa “não mencionar os problemas” da cidade (MARICATO, 2013, p. 171-172). Dentre tantas estratégias, destaca-se neste artigo a instrumentalização como marketing urbano de conceitos em moda no debate sobre inovação que se relacionam com o caso do Porto Digital em três momentos: economia de aglomeração no final do século XX; economia criativa nos anos 2000; e produção maker nos anos 2010.

No final do século XX, estavam em discussão muitos conceitos sobre economia de aglomeração. Houve, inclusive, o resgate de antigas referências, como distrito industrial, do economista Alfred Marshall no final do século XIX, construído com base na observação do padrão de organização de pequenas empresas de manufatura de produtos específicos, concentradas geograficamente, que potencializava uma atmosfera industrial e gerava externalidades (BISCEGLIA, 2014; LASTRES; CASSIOLATO, 2003). Assim, em contraste com a fragmentação da cadeia produtiva em escala global, defendia-se que empresas agrupadas e especializadas poderiam criar uma atmosfera industrial e obter certas vantagens (CROCCO et al., 2006). Isso repercutiu na multiplicação de novas referências.

Com inspiração na Terceira Itália, foram romantizados certos valores humanos e relações de confiança por meio do distrito industrial italiano, definido por Becattini (1989 apud BISCEGLIA, 2014) como uma entidade socioterritorial caracterizada pela ação coexistente da comunidade de pessoas e de empresas industriais que compartilham conduta de valores, expectativas e linguagens comuns. Nessa linha marshalliana, e considerando o ser humano como um ator econômico, Michael Porter (1999) popularizou, nos anos 1990, seu conceito de cluster, entendido como uma concentração geográfica de empresas, distribuidores, fornecedores, instituições e associações dentro de uma mesma cadeia produtiva que, por meio de relacionamentos de forma cooperativa e competitiva, alcançam vantagens econômicas.

No Brasil, um conceito que embasou a construção de política pública nacional foi o Arranjo Produtivo Local (APL), cuja visão é mais sistêmica, na qual são consideradas as relações entre atores diversos, concentrados ou não, com o intuito de diminuir as assimetrias de conhecimento e de promover o desenvolvimento socioeconômico (LASTRES; CASSIOLATO, 2003). Contudo, na prática, a construção de políticas de APL no Brasil seguiu uma linha mais próxima de cluster com foco em um único segmento produtivo concentrado geograficamente (CASSIOLATO; MATOS, 2012). No caso do Porto Digital, sua construção teórica se baseou no posicionamento da universidade e de grupos de pesquisa como quase firmas para a geração de desenvolvimento científico e tecnológico com enfoque na iniciativa privada, mediante o conceito Triple Helix (THERG-BRAZIL, 2016). 
Entretanto, no debate acadêmico, não existe consenso sobre as vantagens econômicas e de inovação no processo de construção de uma economia de aglomeração. Há aqueles que rejeitam totalmente suas propostas, outros que as defendem com maior cautela e, ainda, os que prestam consultoria. Segundo Moreira (2014), essa popularização do conceito de cluster, por exemplo, se deve a um rótulo ou marca cluster.

Consequentemente, surgiram também diversas experiências de propostas de revitalização urbana associadas a desenvolvimento produtivo-inovativo. Alguns exemplos são: Programa Bicocca, um parque científico e tecnológico com moradia e comércio em vazios urbanos da cidade de Milão; Mission Bay, um cluster de biotecnologia em antiga zona portuária e industrial na cidade de São Francisco; 22@Barcelona, uma operação urbana no bairro catalão de Poblenou construída com o emprego dos conceitos de cidade do conhecimento e de distrito industrial italiano; Greater Philadelphia Innovation Cluster (GPIChub), um parque tecnológico "verde" em uma base naval desativada na Filadélfia; e Cité du Multimédia, um cluster de Tecnologias de Informação e Comunicação (TIC) em antigo pátio ferroviário em Montreal.

Já na entrada do século XXI, a economia criativa ou o "mantra da criatividade" passaram a ser "glorificados" como um potencial de criação de riqueza e emprego voltados à classe criativa (SELDIN, 2015). Isso porque, em um mundo cada vez mais globalizado, em que o ineditismo se mantém em menor espaço de tempo, a criatividade, a cultura e a inovação assumiram grande importância como recursos significativos na geração de valor econômico e de diferenciação (GIGLIO; WECHSLER; BRAGOTTO, 2009; SCOTT, 2008). Nesse sentido, Storper e Venables (2005) acreditam que teorias de aglomeração ficaram mais focadas em transações imateriais e de informações, conhecimentos e ideias.

Como rebatimento ao planejamento urbano, passou-se a idealizar o conceito de cidade criativa, que, para atrair pessoas talentosas, deveria promover, além de uma cidade compacta, o respeito à diversidade de gênero, cor e nacionalidade, a inovação tecnológica e uma rica vida cultural (FLORIDA, 2010). Nessa busca por investidores e talentos, as intervenções urbanas deram ênfase à criatividade e à cultura em áreas decadentes, buscando animar espaços públicos e os negócios (GLAESER, 2000).

No entanto, Rausell (2009) reforça que cidade criativa é mais um slogan de city marketing do que de fato a efetivação de uma transformação real maior. Segundo Peck (2015), esse otimismo “criativo” de Florida é um negócio de consultoria para reposicionar cidades-clientes em rankings de "saúde criativa" e para atrair ou "mimar" o consumista "homo creativus", ou seja, a classe média consumista. Para Slater (2015), essa febre de cidade criativa tornou a gentrificação um sinal 
economicamente saudável em razão de sua imagem ligada à última moda, à boemia, a algo cool, com grupos de artistas que ocupam cafés e galerias em bairros abandonados, mas "carentes de criatividade".

Atualmente, com a quarta revolução tecnológica, propagandeia-se também a produção maker (fazedores) ou Do-It-Yourself (DOY; faça você mesmo) como novas possibilidades de um sistema produtivo mais horizontal, colaborativo, distributivo e personalizado. Nos campos da arquitetura e do urbanismo, seus rebatimentos são observados em novas propostas participativas via aplicativos, nos Fab Labs e no urbanismo tático (LYDON et al., 2012), cujas propostas podem desencadear processos de gentrificação, realizados pelos chamados citymakers. Há certa similaridade com a proposta de cidades inteligentes (smart cities), que apresenta com otimismo a ideia de que a tecnologia, além de "prestar de forma mais eficiente os serviços urbanos", permitiria "melhorar a qualidade de vida das pessoas e transformar a relação entre entidades locais, empresas e cidadãos proporcionando uma nova forma de viver na cidade" (CUNHA et al., 2016, p. 28).

De modo geral, trata-se de uma nova onda de discursos "otimistas" e "meritocráticos”, como se não houvesse informação restrita e privilegiada nem leis coercitivas de concorrência e, para se desenvolver, bastasse simplesmente ser criativo e “fazer”. Nogueira e Portinari (2016) ressaltam que o resultado do trabalho coletivo do movimento maker pode não necessariamente ser para todos, mas muito provavelmente se destina à classe criativa que dispõe de tempo para isso. Ao pregar independência e autonomia em relação ao Estado, o movimento diminuiu o engajamento reivindicativo relativo à cobrança de melhorias e de soluções para os problemas da cidade, o que é extremamente conveniente para o neoliberalismo.

Nesse sentido, Cano (2012) critica a ênfase na "teoria do poder local", que consistiria justamente em uma estratégia do neoliberalismo, de atacar profundamente o papel do Estado nacional, pois o poder municipal não poderia substituí-lo na "formulação de políticas de desenvolvimento que transcendam esse espaço restrito e que tenham nexos com os objetivos nacionais de uma política de desenvolvimento", tais como taxa de juros, câmbio, crédito e fiscalidade necessária. Harvey (2014, p. 70-71) afirma que as políticas neoliberais canalizam os recursos para "os polos de crescimento 'empresarial' mais dinâmicos" com discursos em que o "efeito de transbordamento se encarregaria então, no proverbial longo prazo (o que nunca aconteceu), de resolver todas essas desagradáveis desigualdades regionais, espaciais e urbanas”. Para Brandão (2012), esse novo imperialismo da "partilha dos lugares eleitos" cria um "pensamento único localista” sem discussão sobre as verdadeiras questões de desenvolvimento. Nessa literatura localista, as soluções para os trabalhadores seriam qualificação ou empreendedorismo e, para as cidades, sua melhor venda com a "banalização" de conceitos. 
Diante desta explanação, demonstra-se como as diferentes narrativas de inovação foram instrumentalizadas como marketing urbano no caso do Porto Digital ao longo de duas décadas.

\section{Metodologia}

Esta pesquisa explicativa trata da instrumentalização das narrativas de inovação como estratégia de marketing urbano no caso do Porto Digital. A coleta de dados foi feita por meio de pesquisas bibliográficas, documentais, de observação no local e de entrevistas semiestruturadas a indivíduos maiores de 18 anos. Foram adotados os seguintes critérios: i) residentes e trabalhadores; ii) técnicos envolvidos com os projetos; iii) pesquisadores que realizaram algum tipo de investigação sobre o caso; e iv) movimentos de resistência. Por se tratar de uma pesquisa que envolve seres humanos, este projeto foi aprovado junto ao Comitê de Ética em Pesquisa do Hospital Universitário Clementino Fraga Filho da Universidade Federal do Rio de Janeiro, por intermédio da Plataforma Brasil. A ida a campo foi realizada entre os meses de outubro e novembro de 2017. Ao final, são cruzadas as informações sobre as estratégias do Porto Digital que contemplam desenvolvimento produtivo-inovativo, gestão imobiliária, planejamento urbano da cidade do Recife e seus principais impactos.

\section{Porto Digital}

A análise sobre o Porto Digital é apresentada a seguir nas seções 3.1 (Desenvolvimento produtivo-inovativo), sobre a construção da política e suas estratégias ao longo de duas décadas; 3.2 (Gestão imobiliária), sobre sua vertente de geração de renda decorrente do aluguel às empresas "embarcadas"; 3.3 (Planejamento urbano), sobre sua responsabilidade no planejamento urbano da cidade do Recife; e 3.4 (Principais impactos no Centro Expandido), sobretudo no Bairro do Recife.

\subsection{Desenvolvimento produtivo-inovativo}

As primeiras ideias de uma economia de aglomeração em TIC surgiram no Centro de Informática (CIn) da Universidade Federal de Pernambuco (UFPE), com base no conceito Triple Helix. A expectativa era de atrair empresas, criar oportunidades de desenvolvimento tecnológico e gerar empregos para a retenção de seus egressos. A princípio, cogitou-se sua implantação no próprio campus universitário, mas a proposta evoluiu para o Bairro do Recife. Ali, onde se localizou o maior porto das Américas no século XVII, foi implantado, no ano 2000, o novo parque tecnológico Porto Digital (entrevistas 08, 20 out. 2017, com técnico do Porto Digital, e 09, 23 out. 2017, com técnico do Projeto Porto Novo Recife). 
Essa proposta foi muito bem aceita entre acadêmicos, atores privados e públicos e, sobretudo, pelo governador Jarbas Vasconcelos (1999-2006), um dos responsáveis pela implantação do Plano de Revitalização do Bairro do Recife durante sua gestão como prefeito (1993-1996). Em 2000, foi criada a política estadual do Porto Digital com os objetivos de "inserir Pernambuco no cenário tecnológico e inovador do mundo" e contribuir com a revitalização econômica e urbana daquele bairro, mediante a geração de renda e empregos, a ocupação e o restauro de imóveis de valor histórico por equipamentos-âncora e empresas de TIC e a distribuição de oportunidades, considerando a Comunidade do Pilar, uma favela situada no próprio bairro.

Em 2001, a Associação Núcleo de Gestão do Porto Digital foi qualificada como Organização Social (OS) responsável por implantar o modelo de governança, promover a infraestrutura e instalar incubadora no Bairro do Recife. Para atrair empresas ao Porto Digital, a Prefeitura foi traçando algumas estratégias até a criação da Lei municipal $n^{0}$. 17.244/2006, que possibilitou a redução de 60\% na alíquota do Imposto sobre Serviços (ISS), de $5 \%$ para $2 \%$, para as empresas instaladas na delimitação do Porto Digital, no Bairro do Recife (RECIFE, 2006b).

Em 2008, o Ministério do Desenvolvimento, Indústria e Comércio Exterior classificou o Porto Digital como APL. Em 2011, foram incorporadas ao parque as atividades de economia criativa; em 2015, foi a vez do ensino a distância e, em 2016, os serviços de makerspace, por meio do Laboratório de Objetos Urbanos Conectados.

Com isso, o Porto Digital conseguiu estabelecer uma rede com 290 empresas, órgãos governamentais e de fomento, bem como nove mil postos de trabalho e 80 mil $\mathrm{m}^{2}$ de ocupação (entrevista 08, 20 out. 2017, com técnico do Porto Digital). Sua governança é reconhecida em citações em jornais e revistas, eventos e premiações, com destaque para o Prêmio Rodrigo Melo Franco de Andrade, em 2017, promovido pelo Instituto do Patrimônio Histórico e Artístico Nacional (Iphan) na nova categoria de "iniciativas de excelência em gestão compartilhada do Patrimônio Cultural”.

\subsection{Gestão imobiliária}

Durante seus primeiros anos, a OS do Porto Digital explorou uma nova vertente de gestão imobiliária. Isso aconteceu a partir de 2006, no último ano da gestão estadual de Jarbas Vasconcelos e de seu vice, José Mendonça Filho, quando a antiga sede do Banco do Estado de Pernambuco (Bandepe) foi concedida à OS para gerar renda resultante do aluguel de grande parte dos $11.700 \mathrm{~m}^{2}$ a empresas “embarcadas” e, com isso, garantir sua sobrevivência na mudança política (RECIFE, 2006a; entrevista 09, 23 out. 10/2017, técnico do Projeto Porto Novo Recife). 
Posteriormente, novos imóveis foram concedidos ou adquiridos pela OS (Figura 1), cuja remuneração chegou a 58,2\% de suas fontes de recursos em 2011 (PD, 2011). No total, a OS está gerindo imóveis que somam aproximadamente $33.685 \mathrm{~m}^{2}(24.037$ $\mathrm{m}^{2}$ deles em concessão estadual e os restantes $9.648 \mathrm{~m}^{2}$ em sua propriedade) (ALBUQUERQUE; LACERDA, 2017).

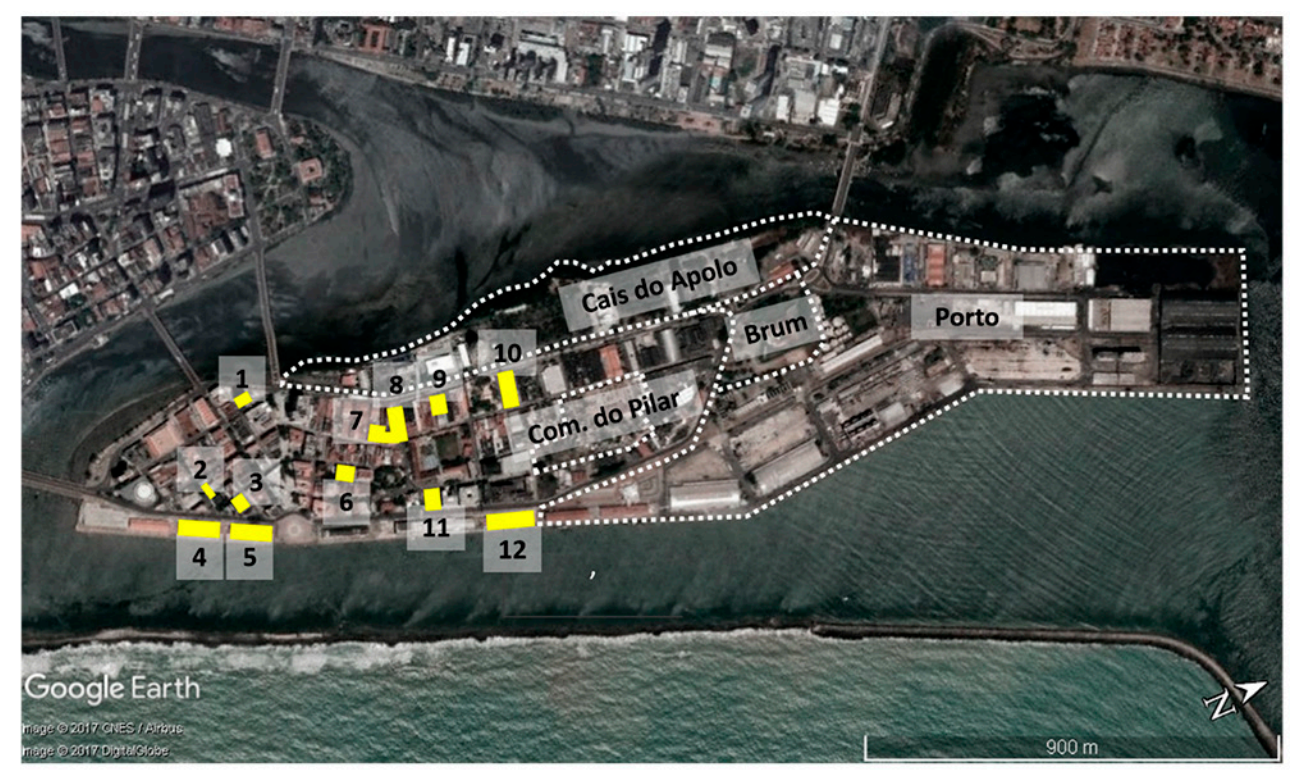

Legenda: (1) Ed. BANDEPE; (2) Moeda, 50; (3) Maria César, 68; (4) Armazém 13; (5) Armazém 12); (6) ITBC/SOFTEX; (7) Ed. Cais do Porto; (8) Ed. Apolo 213 e 215; (9) Cais do Apolo 181; (10) CESAR; (11) SECTMA; e (12) Armazém 9.

Principais edifícios ligados ao parque tecnológico

Outras delimitações

Figura 1. Imóveis adquiridos, concedidos ou relacionados ao Porto Digital no Bairro do Recife Fonte: Elaborada pelos autores (2018).

O portfólio de espaços para aluguel do Porto Digital é apresentado inclusive em eventos nacionais e internacionais do segmento tecnológico (LACERDA; FERNANDES, 2015). Para alguns entrevistados, o Porto Digital tornou-se um "corretor de luxo para atividades TIC”, um “agente imobiliário” ou uma "grande imobiliária” (entrevistas 16, 25 out. 2017, residente do Bairro do Recife, e 21, 30 out. 2017, técnico da Prefeitura). Segundo este último entrevistado: "Eu brinco muito com o pessoal do Porto Digital, que não é mais Porto Digital, é Banco Imobiliário Digital. Porque eles estão comprando tudo, se espalhando... já estão em Santo Amaro”.

Uma de suas recentes ocupações, o Edifício Apolo 235, simboliza de certa forma a transformação do Bairro do Recife. Em 2016, o Porto Digital inaugurou o makerspace Laboratório de Objetos Urbanos Conectados. Embora não se trate de ação incisiva, nos anos 1980 esse edifício foi a Pensão Convento, que abrigava alguns dos “aposentados da 'batalha' da vida naquele sítio histórico” (PCR, 1989, p. 23), conforme Figuras 2 e 3. É representativo também o depoimento de 
Francisca Lopes Gomes, uma de suas antigas moradoras sobre o processo de gentrificação que ainda estava por vir: 'E um ‘Convento’ como esse[,] que podia ficar tão bonito, com as velhas, com esse povo mais cansado morando lá no seu cantinho, de um jeito decente [...] Será que eu nasci aqui e na hora que esse bairro vai se embelezar não vai ter um canto para mim?” (MONTENEGRO et al., 1989, p. 42).

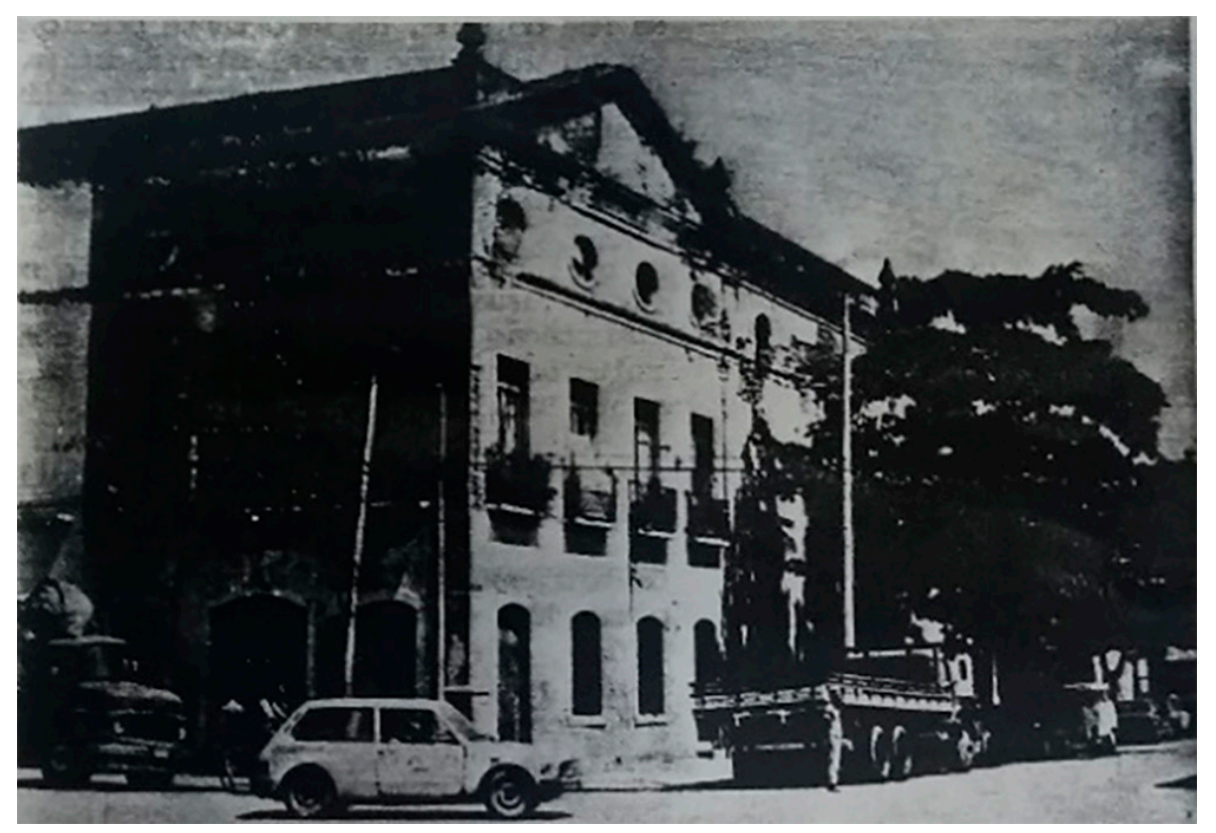

Figura 2. Pensão Convento nos anos 1980 Fonte: PCR, 1989, p. 22

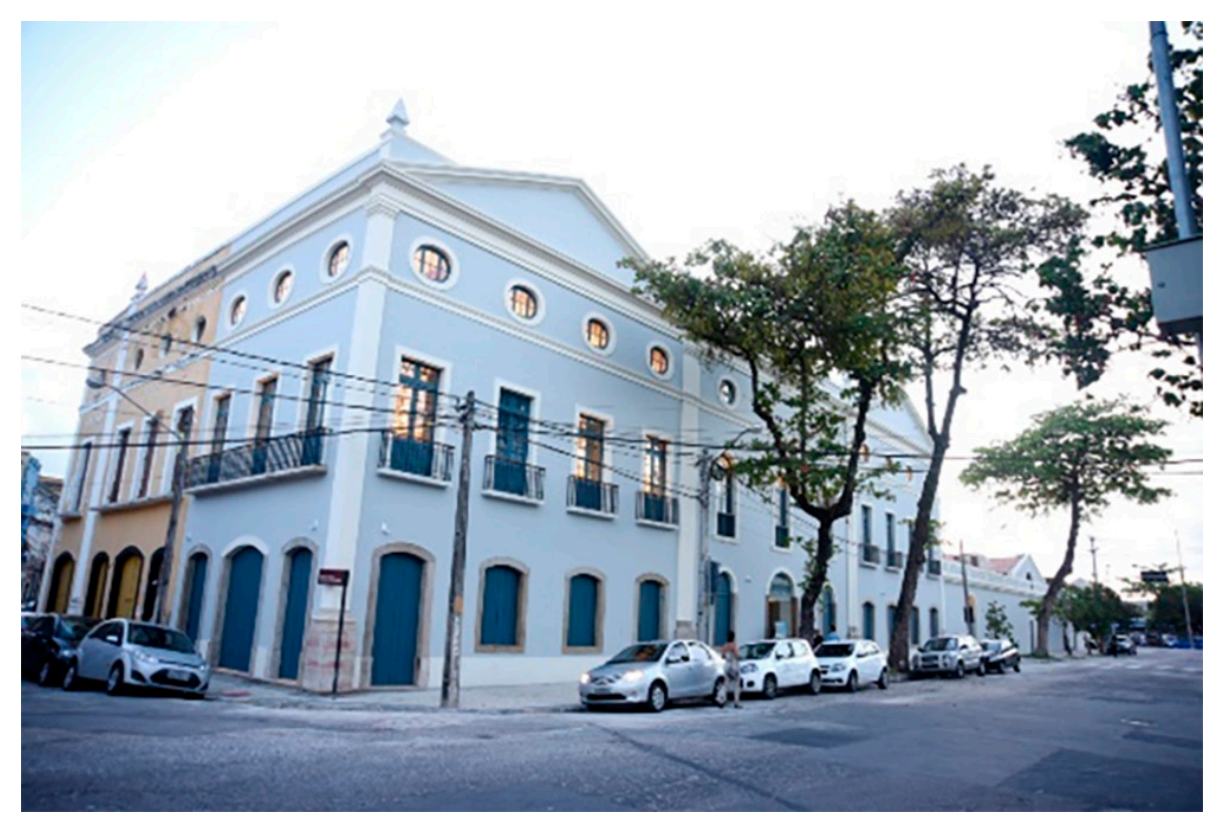

Figura 3. Edifício Apolo 235, inaugurado em 2017 Fonte: PD, 2017. 


\subsection{Planejamento urbano}

Em relação ao planejamento urbano, a OS do Porto Digital foi ganhando expressiva responsabilidade. Em 2006, o Porto Digital foi um dos “capitães” do Projeto Urbanístico Recife-Olinda, uma parceria entre as prefeituras dessas duas cidades, o governo do estado e a empresa pública portuguesa Parque Expo (entrevista 20, 27 out. 2017, com o autor do Plano de Revitalização). A proposta tratou o waterfront portuário (terrenos públicos em sua maioria) como um negócio de porte, projetando-se largamente, como tabula rasa, um novo bairro adensado com uso misto, novas conexões (pontes) e novo terminal marítimo. Embora a proposta não tenha saído do papel, muitas ideias se desdobraram em polêmicos projetos, cujo conjunto pode ser observado na Figura 4.

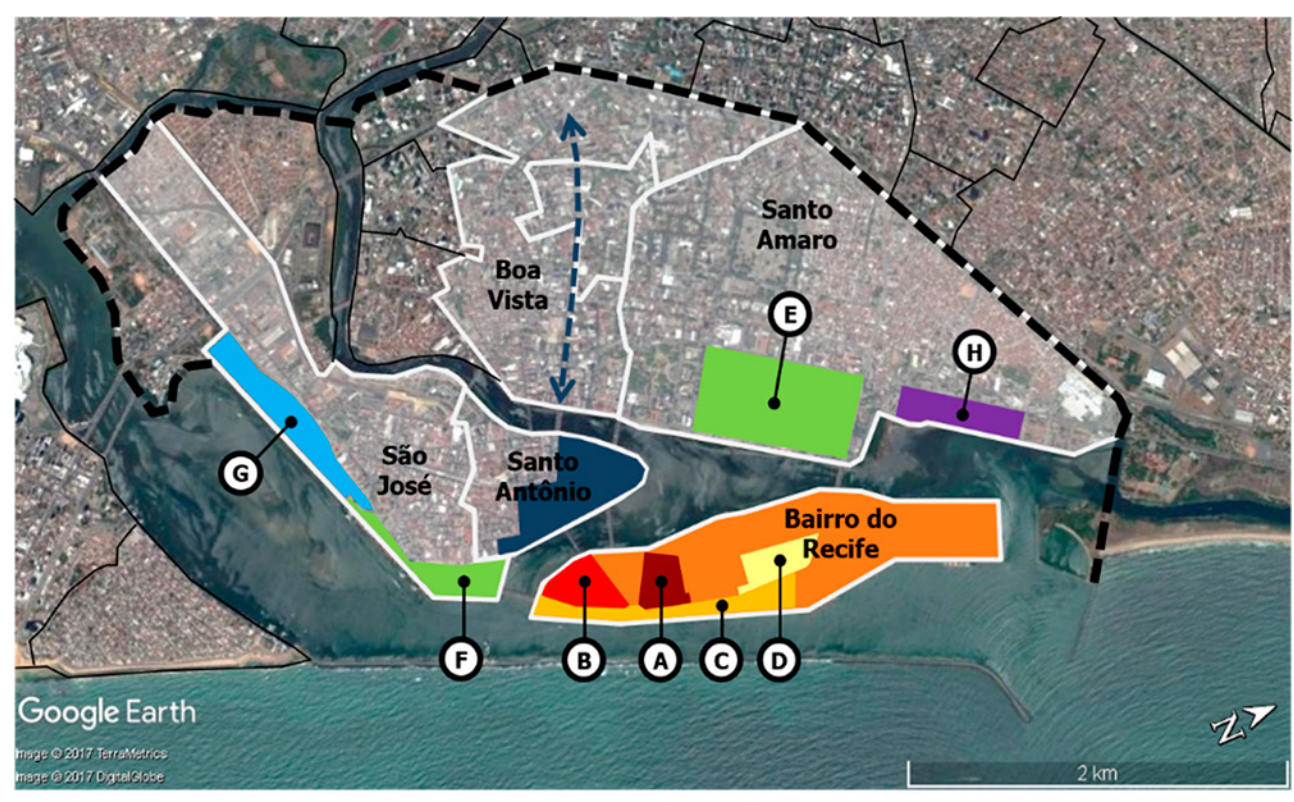

\footnotetext{
- Limite do Centro Expandido

Limite de bairros

(A) A - Polo Bom Jesus; B - Polo Alfândega; C - Waterfront; D - Polo Pilar; E - Quadrilátero de Santo Amaro; F - Cais de Santa Rita; G - Cais José Estelita; H - Vila Naval.

Polo Bom Jesus (1993-1996)

Polo Alfândega (final dos anos 1990-início dos anos 2000)

Porto Digital (2000 - Bairro do Recife)

Waterfront do Bairro do Recife (2007)

Polo Pilar (2010)

Setor de Requalificação do Centro (2008); Porto Digital (2011 - Quadrilátero; 2015 - Cais de Santa Rita).

Projeto Novo Recife (2012).

Porto Digital (2015 - Cais de Santa Rita, Santo Antônio e Av. Conde de Boa Vista).

Vila Naval (2017).
}

Figura 4. Mapeamento das principais intervenções no Centro Expandido do Recife Fonte: Elaborada pelos autores (2020). 
Em 2007, foi elaborado o Projeto Porto Novo Recife para candidatura à cidade-sede da Copa do Mundo de 2014, que resultou, no Bairro do Recife, na consolidação do waterfront portuário como espaço de entretenimento e turismo, assim como na expulsão, em 2008, das 54 famílias da Comunidade Silveira Pescado no Cais de Santa Rita. Em 2008, a Prefeitura criou, com a Lei n. 17.489, a Zona Especial de Centro Principal (ZECP), delimitando setores, com os maiores incentivos urbanísticos (coeficiente de aproveitamento e taxa de ocupação) no Cais de Santa Rita e no “Quadrilátero” de Santo Amaro. Em 2011, o Porto Digital expandiu seus benefícios fiscais para esse "Quadrilátero" e, em 2015, os estendeu para o Cais de Santa Rita, para parte do Bairro de Santo Antônio e para os lotes lindeiros da avenida Conde de Boa Vista. Em 2012, no Cais José Estelita, é apresentado o Projeto Novo Recife, que desde então tem despertado inúmeros movimentos e manifestações de resistência. Em 2017, a Vila Naval recebeu uma proposta de operação urbana que também tem repercutido em uma nova onda de resistência.

Além disso, em 2014, teve início o Plano Recife 500 anos, "por meio da Prefeitura do Recife e o Núcleo de Gestão do Porto Digital”, que firmou um contrato de gestão com uma nova OS: a Agência Recife para Inovação e Estratégia (ARIES), "responsável pela gestão e condução da implementação das ações definidas para o desenvolvimento do Recife” (PCR, 2015, p. 12), até 2037, quingentésimo aniversário da cidade, independentemente da gestão política. Seu discurso ressalta o desafio de reposicionamento estadual e regional de Recife como uma das capitais mais antigas, ignorando-se, porém, que se trata da capital mais desigual do Brasil. Ou seja, conciliam-se o fetiche e o romantismo entre seu passado e seu futuro e as novas ferramentas digitais de construção coletiva e hashtags, mas se finge não perceber seus problemas sociais do presente.

\subsection{Principais impactos no Centro Expandido}

Durante os anos 1990, o Bairro do Recife passou por um processo de revitalização na parte sul da ilha, mais especificamente no Marco Zero e nos polos Bom Jesus e Alfândega. Assim, na virada do século XXI, a ilha se encontrava em efervescência de entretenimento e turismo, ao mesmo tempo que havia espaços valorizados e subutilizados, em decorrência do êxodo de parte de antigos residentes da parte sul da ilha e da ocupação predominantemente térrea por bares e restaurantes (LEITE, 2006; MORIM DE MELO, 2003). Para consolidar a PPP, era necessário atrair investidores que pudessem custear a recuperação de edifícios e sua ocupação. Considerando que o metro quadrado de escritório geralmente é mais caro do que o de habitação, as atividades TIC do Porto Digital poderiam estar na frente 
desse avanço de fronteira, com a vantagem de não gerar poluição atmosférica e não conflitar com o núcleo urbano, as atividades de entretenimento e turismo e a tipologia arquitetônica.

Contudo, apesar das incubadoras, um dos primeiros impactos da implantação do Porto Digital e do benefício fiscal foi a transferência de empresas de uma parte da cidade para outra (entrevista 20, 27 out. 2017, autor do Plano de Revitalização). Para a cidade, isso reproduz um modelo com menor diversidade ao longo de seu território, maior concentração de espaços de trabalho em uma centralidade e mais deslocamentos pendulares, muitos realizados com o uso de automóvel em função da condição financeira de seus trabalhadores e clientes. Para o Bairro do Recife, essa transferência de empresas significa a transferência de riquezas.

Ademais, Albuquerque e Lacerda (2017) questionam o fato de que esse incentivo não exige contrapartida no processo de revitalização e impacta no desestímulo à diversificação de uso e de ocupação do solo, pois um setor econômico específico se torna privilegiado diante dos demais.

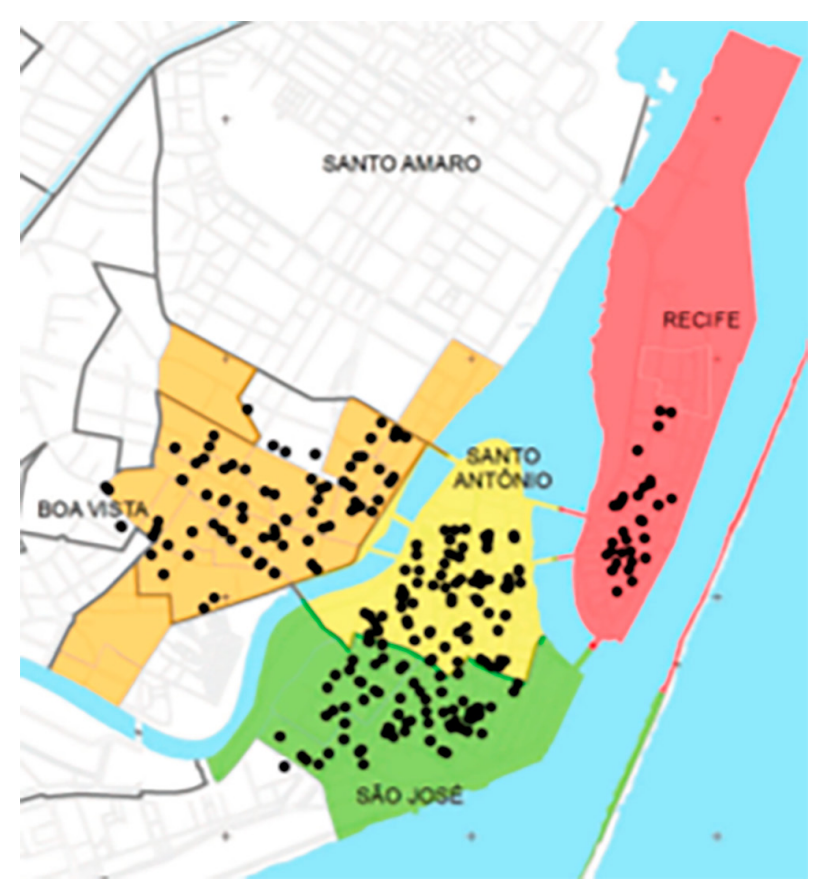

Figura 5. Localização de imóveis vendidos (ITBI) entre 2008 e 2013 Fonte: Lacerda e Fernandes (2015, p. 346)

Com tantas transformações, o Bairro do Recife passa por uma valorização superior à dos bairros vizinhos, com muitas transações, na parte sul da ilha, de imóveis de uso comercial em detrimento dos residenciais, conforme Figura 5 e 
Tabelas 1 e 2. Santo Antônio tem proporção semelhante à do Bairro de Recife, mas com números absolutos maiores. Boa Vista apresenta maior número de transações e maior proporção de imóveis residenciais sobre comerciais, entretanto seus números foram decrescentes nesse período. Em São José, os números são mais equilibrados nessa relação e as transações de imóveis residenciais foram crescentes no período analisado.

\begin{tabular}{c|c|c|c|c|c|c|c|c}
\hline \multirow{2}{*}{} & \multicolumn{2}{|c|}{ Boa Vista } & \multicolumn{2}{c|}{ Recife } & \multicolumn{2}{c|}{ Santo Antonio } & \multicolumn{2}{c}{ São José } \\
\cline { 2 - 9 } & Com. & Res. & Com. & Res. & Com. & Res. & Com. & Res. \\
\hline 2008 & $1.077,31$ & $1.028,85$ & $1.041,44$ & - & 795,15 & $589,40^{*}$ & $1.359,37$ & 840,49 \\
\hline 2009 & $1.293,20$ & $1.066,49$ & $1.747,37$ & - & 927,16 & 989,77 & $2.416,77$ & 608,99 \\
\hline 2010 & $1.329,57$ & $1.160,89$ & $1.965,09$ & - & $1.041,69$ & 811,22 & $1.488,25$ & 567,78 \\
\hline 2011 & $1.327,40$ & $1.423,78$ & $1.506,60$ & $2.425,60$ & $1.215,62$ & 895,58 & $2.191,73$ & 601,09 \\
\hline 2012 & $1.645,50$ & 1871,16 & $1.770,53$ & - & $1.503,05$ & $2.450,53\left(^{\star}\right)$ & $2.081,83$ & $1.511,01$ \\
\hline 2013 & $1.711,67$ & $2.101,60$ & $2.413,79$ & - & $1.137,50$ & - & $1.921,19$ & $1.044,94$ \\
\hline Var. $(\%)$ & 58,88 & 104,27 & 131,77 & - & 43,05 & - & 41,33 & 24,33 \\
\hline
\end{tabular}

Tabela 1. Evolução dos preços médios anuais do metro quadrado no Centro do Recife

Notas: os dados apresentados são referentes aos imóveis com Imposto de Transmissão de Bens Imóveis regularizado entre janeiro de 2008 e outubro de 2013, com valores atualizados pelo índice de correção monetária IGP-M/FGV, em março de 2014; $\left(^{*}\right)$ Preço correspondente a um único imóvel transacionado.

Fonte: Fonte: Lacerda e Anjos (2015, p. 477).

\begin{tabular}{c|c|c|c|c|c|c|c|c}
\hline \multirow{2}{*}{} & \multicolumn{2}{|c|}{ Boa Vista } & \multicolumn{2}{c|}{ Recife } & \multicolumn{2}{c|}{ Santo Antonio } & \multicolumn{2}{c}{ São José } \\
\cline { 2 - 9 } & Com. & Res. & Com. & Res. & Com. & Res. & Com. & Res. \\
\hline 2008 & 81 & 96 & 8 & - & 72 & 1 & 12 & 5 \\
\hline 2009 & 67 & 85 & 9 & - & 65 & 4 & 16 & 5 \\
\hline 2010 & 84 & 90 & 5 & - & 84 & 2 & 18 & 9 \\
\hline 2011 & 58 & 90 & 13 & 1 & 71 & 5 & 24 & 15 \\
\hline 2012 & 71 & 90 & 13 & - & 74 & 1 & 19 & 40 \\
\hline 2013 & 55 & 57 & 7 & - & 103 & 0 & 12 & 22 \\
\hline Total & 1.041 & 508 & 55 & 1 & 469 & 13 & 101 & 96 \\
\hline
\end{tabular}

Tabela 2. Imóveis transacionados mediante compra e venda por ano

Notas: os dados apresentados são referentes aos imóveis com ITBI regularizado entre janeiro de 2008 e outubro de 2013.

Fonte: Fonte: Lacerda e Anjos (2015, p. 477).

Em Santo Antônio, grande parte dos 482 imóveis transacionados entre 2008 e 2013 (do estoque de 1.470) foi ocupada por estabelecimentos de ensino superior que posteriormente foram agraciados com a expansão do Porto Digital. Acredita-se que o predomínio de aluguéis comerciais e de serviços no Centro 
Histórico do Recife (CHR) - 60,12\% de uma amostra de 168 endereços - esteja ligado ao estímulo destinado ao parque tecnológico. "Ressalte-se, ainda, que os bairros do entorno do CHR vêm, a partir dos anos 2010, despertando o interesse do setor imobiliário de unidades habitacionais novas” (LACERDA, 2018, p. 125).

Entre os censos demográficos de 2000 e 2010, houve diminuição de 925 para 602 habitantes e de 288 para 198 domicílios no Bairro do Recife (ADHR, 2005; PCR, 2016). Parte expressiva dessa população reside na Comunidade do Pilar e tem suas características contrastadas com as da população trabalhadora das empresas “embarcadas” no Porto Digital. Em relação à escolaridade, observa-se a disparidade entre os $66,9 \%$ dos trabalhadores com superior completo e os $18,3 \%$ dos residentes analfabetos. No tocante à renda, $78,3 \%$ dos trabalhadores do Porto Digital estão empregados sob a Consolidação das Leis do Trabalho (CLT) contra somente $25,82 \%$ de emprego formal dos chefes das famílias do Pilar. Quanto ao sexo, a maioria dos trabalhadores do Porto Digital é do sexo masculino $(66,4 \%)$, enquanto na Comunidade a maioria dos chefes de família é do sexo feminino (59,72\%). No que concerne à idade, enquanto é comum para um profissional da classe criativa concluir sua graduação até os 25 anos, os filhos e os netos das famílias do Pilar assumiram a responsabilidade de obter renda. Apesar de não haver dados relacionados à cor dos trabalhadores do Porto Digital, não se observa predominância de negros e pardos, tal como ocorre na Comunidade do Pilar (PD, 2012; PCR, 2012, 2016). A Tabela 3 revela ainda a estrutura machista desse conjunto de empresas, em que a maior remuneração cabe aos profissionais do sexo masculino.

\begin{tabular}{l|c|c|c}
\hline Área & Feminino & Masculino & Razão Masc./Fem. (\%) \\
\hline Operador de telemarketing & 661,60 & 817,56 & $123 \%$ \\
\hline Estagiário & 765,35 & 781,29 & $102 \%$ \\
\hline Administrativa & $1.721,32$ & $1.366,57$ & $79 \%$ \\
\hline Vendas & $2.816,67$ & $3.195,71$ & $113 \%$ \\
\hline Técnica & $2.519,14$ & $2.551,94$ & $101 \%$ \\
\hline Gestão & $4.763,04$ & $5.772,82$ & $121 \%$ \\
\hline
\end{tabular}

Tabela 3. Média salarial por sexo e por área dos trabalhadores do Porto Digital Fonte: PD, 2012, p. 55.

\section{Discussão}

O discurso "otimista” sobre economia de aglomeração, economia criativa e produção maker permite observar que o Porto Digital não influencia somente a esfera produtivo-inovativa de Recife, mas também aquelas nos âmbitos social e urbano. Os incentivos fiscais exercem influência direta nas atividades dos bairros afetados, 
distorcendo o mercado em favor de seus segmentos. Essa estratégia de "estabelecimento de políticas para o benefício de determinadas empresas”, até mesmo para o consultor de cluster Michael Porter (1999, p. 264), "distorce o mercado e utiliza de forma ineficiente os recursos governamentais”. Ademais, em um primeiro momento, houve migração de empresas para o Bairro do Recife. Isso significa, para a capital pernambucana, uma cidade mais setorizada, dispersa e com maior número de deslocamentos pendulares. Para o objetivo da gentrificação, essa transferência de empresas significa a transferência de riquezas.

Posteriormente, a OS do Porto Digital recebeu concessão de imóveis públicos e adquiriu outros com o objetivo de restaurá-los e alugá-los às empresas "embarcadas”. É importante reconhecer a responsabilidade do Porto Digital na preservação do patrimônio edificado do Bairro do Recife, inclusive com premiação do Iphan. É claro que isso também contribuiu para a identidade e o marketing desse negócio. Trata-se do "charme” adicional que, segundo Lacerda e Fernandes (2015), os parques tecnológicos poderiam adquirir em um sítio histórico. No entanto, tais imóveis são esvaziados de outras funções sociais porque não há nessa gestão o estabelecimento de cotas para os demais usos, como habitação de interesse social. Prevalecem, pois, a monofuncionalidade e os interesses imobiliários. Para esses autores (LACERDA; FERNANDES, 2015, p. 350):

[...] a face da moeda representada pelos coadjuvantes efeitos rentistas - bastante sedutores - provavelmente brilha mais aos olhos de setores da gestão e operação do parque do que a face da elevação das competências inovativas das empresas que ali decidem se instalar.

Além dessas questões que influenciam diretamente o desenvolvimento urbano, a OS do Porto Digital assume maior protagonismo no planejamento urbano, com destaque para diversas oportunidades de negócios imobiliários em terrenos públicos, tais como o waterfront do Bairro do Recife, o Cais José Estelita, a Vila Naval, o "Quadrilátero” de Santo Amaro e o Cais de Santa Rita. Embora vários atores estejam envolvidos, esse conjunto de processos de gentrificação aparenta se comportar, tal como conceituado por Smith (2012), com "avanços na fronteira da gentrificação". Aos poucos, os territórios deprimidos de investimentos são "reconquistados", no caso específico, por promotores imobiliários, empresas, "classe criativa” e a própria OS do Porto Digital, que consiste em uma grande administradora/ proprietária de imóveis e agente do planejamento urbano.

É contraditório o fato de que, com tanta responsabilidade no planejamento urbano e dispondo de tantos recursos públicos, a OS delegue seus compromissos sociais às empresas "embarcadas" na busca por um selo de responsabilidade. 
A esse respeito, Fransen (2012) alerta que as políticas de cluster em países periféricos tendem a fortalecer as assimetrias em face das condições desiguais de renda, escolaridade e de negócios internacionais. Assim, as instalações de ponta do Porto Digital proporcionam maiores e fascinantes oportunidades de empreendedorismo à classe criativa e prometem resolver problemas em geral pertinentes a essa classe. Entretanto, são poucos os esforços para oferecer oportunidades semelhantes à população das comunidades, sobretudo mulheres negras que chefiam suas famílias; para evitar os problemas de gentrificação em curso causados pelos diversos atores atuantes no Centro Expandido; para solucionar o esgoto a céu aberto na Comunidade do Pilar; ou mesmo para debater outros usos no estoque imobiliário gerido pela OS.

Atualmente, com o Recife 500 anos, uma nova OS assume pelas próximas décadas o papel de planejamento da cidade que deveria ser desempenhado pelo poder público. Com tantas evidências sobre a prioridade dada aos negócios imobiliários em detrimento da diminuição das desigualdades da cidade, torna-se preocupante o destino da capital mais desigual do Brasil.

\section{Considerações finais}

Ao longo de duas décadas, o Porto Digital demonstrou ser extremamente dinâmico. Ao afastar-se de alguns de seus propósitos iniciais, ganhou maior autonomia do poder público e renovou suas estratégias e discursos sobre inovação. Aos negócios, são ofertados inúmeros incentivos e oportunidades. Apesar do desenvolvimento produtivo-inovativo, que incorpora o telemarketing como atividade "criativa”, suas campanhas de inovação tornaram-se um artifício de marketing urbano para ganho de capital simbólico na operação urbana e para a promoção de otimismo nos negócios em detrimento da superação das desigualdades da cidade. Nos bairros afetados, observam-se manipulação de identidade, valorização imobiliária, êxodo de população de baixa renda e ingresso de nova população das empresas “embarcadas”. Ou seja, são processos de gentrificação que pouco a pouco vão reconquistando territórios antes deprimidos de investimentos no Centro Expandido do Recife. A permanência dos menos favorecidos nesses territórios não é desejada, tal como se verificou na expulsão da Comunidade Silveira Pescado ou na redução da população residente no Bairro do Recife. Com isso, seja pela economia de aglomeração, seja pela economia criativa e/ou maker, observa-se o potencial de sedução do discurso de inovação, instrumentalizado como marketing urbano para manter seu "otimismo" em relação aos negócios e para fazer uma "cortina de fumaça” para as desigualdades acirradas. 


\section{Referências}

ALBUQUERQUE, I. J. C.; LACERDA, N. Normas indutoras e interesse público: o Porto Digital (Bairro do Recife) e captura da coisa pública. In: ENCONTRO NACIONAL DA ANPUR, 17., 2017. São Paulo: Anpur, v. 1, p. 1, 2017. Tema: Desenvolvimento, crise e resistência: quais os caminhos do planejamento urbano e regional?.

ATLAS DE DESENVOLVIMENTO HUMANO NO RECIFE (ADHR). Software 2005. Versão 1.0.2. Disponível em: https://www.recife.pe.gov.br/pr/secplanejamento/pnud2006/. Acesso em: 10 nov. 2017.

ARANTES, O. Uma estratégia fatal: A cultura nas novas gestões urbanas. In: ARANTES, O.; VAINER, C.; MARICATO, E. (org.). A cidade do pensamento único: desmanchando consensos. Petrópolis: Vozes, 2013. p. 11-74.

BISCEGLIA, R. Local economies in times of crisis: Italian Industrial Districts experience. International Link and Services for Local Economic Development Agencies, n. 22, jan. 2014.

BRANDÃO, C. Território e desenvolvimento: as múltiplas escalas entre o local e o global. Campinas: Ed. da Unicamp, 2012.

CANO, W. Prefácio. In: BRANDÃO, C. Território e desenvolvimento: as múltiplas escalas entre o local e o global. Campinas: Ed. da Unicamp, 2012. p. 23-28.

CASSIOLATO, J. E.; MATOS, M. G. P. Política brasileira para Arranjos Produtivos Locais: o aprendizado acumulado e suas perspectivas. In: LASTRES, H. M. M. et al. (org.). A nova geração de políticas de desenvolvimento produtivo? Sustentabilidade social e ambiental. Brasília, DF: Confederação Nacional da Indústria, 2012. p. 187-201.

CROCCO, M. A. et al. Metodologia de identificação de aglomerações produtivas locais. Nova Economia, v. 16, n. 2, p. 211-241, 2006.

COMPANS, R. Empreendedorismo urbano: entre o discurso e a prática. São Paulo: Ed. da Unesp, 2005.

CUNHA, M. A. et al. Smart cities: transformação digital de cidades. São Paulo: Programa Gestão Pública e Cidadania, 2016. p. 28.

DELGADO, M. La ciudad mentirosa: fraude y miseria del "Modelo Barcelona”. S.l.: Catarata, 2010.

FLORIDA, R. L. O grande recomeço: as mudanças no estilo de vida e de trabalho que podem levar à prosperidade pós-crise. Rio de Janeiro: Elsevier, 2010.

FRANSEN, J. Transições urbanas de desequilíbrio. De artesanatos a objetos de decoração na Cidade do Cabo. In: CAVALLAZZI, R. L.; PARAIZO, R. C. (org.). Patrimônio, ambiente e sociedade - novos desafios espaciais. Rio de Janeiro: PROURB, 2012. p. 77-115.

GIGLIO, Z. G.; WECHSLER, S. M.; BRAGOTTO, D. Da criatividade à inovação. Campinas: Papirus, 2009.

GLAESER, E. L. The new economics of urban and regional growth. In: CLARK, G.; FELDMAN, M.; GERTLER, M. (org.). The Oxford Handbook of Economic Geography. Oxford: Oxford University Press, 2000. p. 83-98. 
HARVEY, D. Cidades rebeldes: do direito à cidade à revolução urbana. São Paulo: Martins Fontes, 2014.

LACERDA, N. Mercado imobiliário de bens patrimoniais: um modelo interpretativo a partir do Centro Histórico do Recife (Brasil). EURE - Revista Latinoamericana de Estudios Urbanos Regionales, v. 44, p. 113-132, 2018.

LACERDA, N.; ANJOS, K. L. Regulação da dinâmica espacial nos centros históricos brasileiros em tempos de globalização: o caso do Recife (Brasil). In: FERNANDES, A. C.; LACERDA, N.; PONTUAL, V. (org.). Desenvolvimento, planejamento e governança: expressões do debate contemporâneo. Rio de Janeiro: Letra Capital, 2015. p. 455-482.

LACERDA, N.; FERNANDES, A. C. Parques tecnológicos: entre a inovação e renda imobiliária no contexto da metrópole recifense (Brasil). Cadernos Metrópole (PUCSP), v. 17, p. 329-354, 2015 .

LASTRES, H. M. M.; CASSIOLATO, J. E. Arranjos Produtivos Locais: uma nova estratégia de ação para o Sebrae. Glossário de arranjos e sistemas produtivos e inovativos locais. Rio de Janeiro: Sebrae, 2003.

LEITE, R. P. Patrimônio e enobrecimento no Bairro do Recife. Revista CPC (USP), São Paulo, V. 2, p. 14-26, 2006.

LIMA JUNIOR, P. de N. Uma estratégia chamada "planejamento estratégico": deslocamentos espaciais e a atribuição de sentidos na terapia do planejamento urbano. Rio de Janeiro: 7Letras, 2010.

LYDON, M. et al. Tactical urbanism. Washington: Island Press, 2012. v. 2: Short-term action for long-term change.

MARICATO, E. As ideias fora do lugar e o lugar fora das ideias: Planejamento urbano no Brasil. In: ARANTES, O.; VAINER, C.; MARICATO, E. (org.). A cidade do pensamento único: desmanchando consensos. Petrópolis: Vozes, 2013.

MONTENEGRO, A. T.; SALES, I. da C.; COIMBRA, S. R. Memória em Movimento: Bairro do Recife, Porto de muitas histórias. Recife: Gráfica Recife, 1989.

MOREIRA, R. A. Política de clusters - o conceito de cluster enquanto catalisador do desenvolvimento territorial - as EEC do QREN. 2014. Dissertação (Mestrado) - Instituto de Geografia e Ordenamento do Território da Universidade de Lisboa, Lisboa, 2014.

MORIM DE MELO, J. Mais além da rua do Bom Jesus: a revitalização do Bairro do Recife, a população e outros usos do local. 2003. Dissertação (Mestrado) - Universidade Federal de Pernambuco, Recife, 2003.

NOGUEIRA, P. C. E.; PORTINARI, D. B. Urbanismo tático e a cidade neoliberal. Revista Arcos Design, v. 9, p. 177-188, 2016.

OBSERVATORIO METROPOLITANO DE MADRID (OMM). El mercado contra la ciudad: sobre globalización, gentrificación y políticas urbanas. Madrid: Traficantes de sueños, 2015.

PREFEITURA DA CIDADE DO RECIFE (PCR). Relatório de Atividades - Memória em Movimento. Recife: Serviço de Pesquisa e Documentação no Bairro do Recife, 1989. 
PREFEITURA DA CIDADE DO RECIFE (PCR). Diagnóstico socioeconômico da Comunidade do Pilar: Programa de Requalificação Urbana e Inclusão Social da Comunidade do Pilar. Recife: Empresa de Urbanização do Recife, 2012.

Primeiro relatório técnico de execução, janeiro a junho de 2015. Contrato de gestão n. 004/2014, Projeto ARIES - Agência Recife para Inovação e Estratégia. Recife: [s. n.], 2015 .

. Bairro do Recife. Disponível em: http://www2.recife.pe.gov.br/servico/bairro-do-recife. Acesso em: 29 set. 2016.

PORTO DIGITAL (PD). \$ustentabilidade dos parques tecnológicos: sustentabilidade financeira e competitividade do território. In: WORKSHOP ANPROTEC, 19., 2011. Porto Alegre: Associação Nacional de Entidades Promotoras de Empreendimentos Inovadores, 2011.

Pesquisa Porto Digital 2012. Disponível em: http://www.portodigital.org/parque/o-que-e-o-porto-digital/documentacao. Acesso em: 5 dez. 2017.

. O que é o Porto Digital. Disponível em: http://www.portodigital.org/parque/o-que-e-o-porto-digital. Acesso em: 25 nov. 2017.

PECK, J. A vueltas con la clase creativa. In: OMM (org.). El mercado contra la ciudad: sobre globalización, gentrificación y políticas urbanas. Madrid: Traficantes de sueños, 2015. p. 53-106.

PORTER, M. E. Competição = On competition: estratégias competitivas essenciais. Rio de Janeiro: Campus, 1999.

RAUSELL, P. Las ciudades creativas: hurgando en el slogan. In: MANITO, F. (org.). Ciudades creativas. Barcelona: Kreanta, 2009. v. 1 - Cultura, territorio, economía y ciudad. p. 77-88.

RECIFE. Lei no. 17.186, de 16 de janeiro de 2006. Diário Oficial da Prefeitura do Recife. Recife: Câmara Municipal, 2006a.

. Lei no. 17.244, de 27 de julho de 2006. Diário Oficial da Prefeitura do Recife. Recife: Câmara Municipal, 2006b.

SANTOS, M. A natureza do espaço: técnica e tempo, razão e emoção. São Paulo: EDUSP, 2006. p. 160 .

SCOTT, A. J. Social economy of the metropolis: cognitive-cultural capitalism and the global resurgence of cities. New York: Oxford University Press, 2008.

SELDIN, C. Da capital de cultura à cidade criativa: resistências a paradigmas urbanos sob a inspiração de Berlim. 2015. Tese (Doutorado) - Universidade Federal do Rio de Janeiro, Rio de Janeiro, 2015.

SIMAS, T. B. A competição das cidades pela inovação e os processos de gentrificação nos casos Porto Digital em Recife e 22@Barcelona. 2018. Tese (Doutorado) - Universidade Federal do Rio de Janeiro, Rio de Janeiro, 2018.

SLATER, T. La expulsión de las perspectivas críticas en la investigación sobre gentrificación. In: OMM (org.). El mercado contra la ciudad: sobre globalización, gentrificación y políticas urbanas. Madrid: Traficantes de sueños, 2015. p. 107-144. 
SMITH, N. La nueva frontera urbana: ciudad revanchista y gentrificación. Madrid: Traficantes de Sueños, 2012.

Nuevo globalismo y nuevo urbanismo. La gentrificación como estrategia urbana global. In: OMM (org.). El mercado contra la ciudad: sobre globalización, gentrificación y políticas urbanas. Madrid: Traficantes de sueños, 2015. p. 245-273.

STORPER, M.; VENABLES, A. J. O burburinho: a força econômica da cidade. In: DINIZ, C. C.; LEMOS, M. B. (org.). Economia e território. Belo Horizonte: Ed. UFMG, 2005. p. 21-56.

THERG-BRAZIL. Triple Helix Research Group Brazil. 2016. Disponível em: http://www.triple-helix.uff.br/sobre.html. Acesso em: 16 dez. 2016.

VAINER, C. Pátria, empresa e mercadoria. In: ARANTES, O.; VAINER, C.; MARICATO, E. (org.). A cidade do pensamento único: desmanchando consensos. Petrópolis: Vozes, 2013. p. 75-104. 


\section{Tarciso Binoti Simas}

Graduado em Arquitetura e Urbanismo pela Universidade Federal do Rio de Janeiro (UFRJ), com mestrado em Engenharia de Transportes no PET/COPPE/UFRJ) e Doutorado em Urbanismo pela mesma instituição (PROURB/UFRJ). É professor adjunto do Instituto de Engenharia do Araguaia da Universidade Federal do Sul e Sudeste do Pará (IEA/Unifesspa)

Email: tarcisobinoti@gmail.com

ORCID: 0000-0002-1687-7582

Contribuição de autoria: conceituação; curadoria de dados; análise formal; investigação/pesquisa; metodologia; administração do projeto; recursos; validação; visualização; escrita - primeira redação; escrita - revisão e edição.

\section{Sônia Azevedo Le Cocq d'Oliveira}

Graduada em Arquitetura e Urbanismo pela Universidade Federal do Rio de Janeiro (UFRJ), com mestrado em Planejamento Urbano e Regional pelo IPPUR/UFRJ e doutorado em Sociologia e Antropologia pelo PPGSA/UFRJ. É professora adjunta do Programa de Pós-graduação em Urbanismo da Faculdade de Arquitetura e Urbanismo da UFRJ.

Email: sonialecocq@gmail.com

ORCID: 0000-0001-7171-4818

Contribuição de autoria: conceituação; análise formal; investigação/pesquisa; metodologia; administração do projeto; supervisão/orientação; validação; escrita revisão e edição. 


\section{Carlos Maviael de Carvalho}

Graduado em Engenharia de Materiais pela Universidade Federal da Paraíba (UFPB), com mestrado em Engenharia de Materiais e doutorado em Ciência e Engenharia de Materiais pelo PPCEM/UFPB. É professor adjunto do Instituto de Engenharia do Araguaia da Universidade Federal do Sul e Sudeste do Pará (IEA/Unifesspa).

Email: maviael.carvalho@gmail.com

ORCID: 0000-0002-7777-4659

Contribuição de autoria: análise formal; investigação/pesquisa; metodologia; validação; visualização; escrita - revisão e edição.

Submissão: 5 de junho de 2020.

Aprovação: 16 de setembro de 2020.

Como citar: SiMAS, T. B.; OLIVEIRA, S. L. C. de; CARVALHO, C. M. As estratégias de marketing urbano do Porto Digital. Revista brasileira de estudos urbanos e regionais. v. 22, e202037pt, 2020.DOI 10.22296/2317-1529.rbeur.202037pt

Artigo licenciado sob Licença Creative Commons CC BY 4.0. https://creativecommons.org/licenses/by/4.o/deed.pt_BR 